\title{
Pengaruh Kegiatan Literasi Terhadap Minat Baca Siswa di Sekolah Dasar
}

\section{Tarmidzi ${ }^{1}$, Widia Astuti ${ }^{2}$}

1Prodi PGSD Universitas Swadaya Gunung Jati Cirebon; mulyatarmidzi@gmail.com 2Prodi PGSD Universitas Swadaya Gunung Jati Cirebon; widiaastuti151@gmail.com

\begin{abstract}
Abstrak. Siswa yang unggul dan mampu bersaing pada abad 21 dapat terwujud apabila memiliki sumber informasi yang sangat luas. Informasi bisa didapat dengan cara membaca. Sumber belajar yang digunakan guru sudah beragam. Namun, perkembangan teknologi informasi tidak menunjukkan siswa gemar membaca, karena kegiatan siswa bermain gadget tidak digunakan untuk belajar, melainkan lebih cenderung digunakan untuk bermain sosial media dan permainan digital. Tujuan untuk mengetahui pengaruh kegiatan literasi dalam upaya sekolah untuk meningkatkan minat baca siswa Sekolah Dasar (SD), karena dengan tingginya minat baca seseorang dapat berpengaruh terhadap wawasan dan tingkah lakunya. Penelitian ini merupakan penelitian kualitatif dengan metode deskripsi. Subjek penelitian ini adalah siswa pada salah satu SD Negeri di Kota Cirebon. Objek penelitian adalah pengelolaan kegiatan literasi, yakni 1) tahapan program; 2) verifikasi dan teknik review; serta 3) akhir program. Data yang terkumpul kemudian dideskripsikan dan dianalisis secara kualitatif. Hasil yang diperoleh dari kegiatan literasi Cirebon Leader's Reading Challenge (CLRC) ini memperlihatkan minat baca siswa yang baik, sehingga dapat disimpulkan bahwa kegiatan literasi memengaruhi minat baca siswa di Sekolah Dasar.
\end{abstract}

Kata kunci: Literasi, Minat Baca, Siswa Sekolah Dasar

Abstract. Students who excel and are able to compete in the 21st century can be realized if they have a very broad source of information. Information can be obtained by reading. Learning resources used by teachers are varied. However, the development of information technology does not show students love to read, because the activities of students playing gadgets are not used for learning, but rather are more likely to be used to play social media and digital games. The aim is to determine the effect of literacy activities in school efforts to increase elementary school students' interest in reading, because with the high interest in reading someone can influence their insight and behavior. This research is a qualitative research with a description method. The subjects of this study were students at one of the elementary schools in the city of Cirebon. The object of research is the management of

Caruban: Jurnal Ilmiah Pendidikan Dasar 3(1), 40-51, Januari 2020

DOI: http://dx.doi.org/10.33603/.v3i1.3361, p-ISSN 2615-1391, e-ISSN 2620-3219

CProdi PGSD Universitas Swadaya Gunung Jati 
literacy activities, namely 1) the stages of the program; 2) verification and review techniques; and 3) end of the program. The data collected is then described and analyzed qualitatively. The results obtained from the Cirebon Leader's Reading Challenge (CLRC) literacy activity show a good student interest in reading, so it can be concluded that literacy activities affect students' interest in reading in elementary schools.

Keywords: Literacy, Interest in Reading, Elementary School Students

\section{Pendahuluan}

Pada abad 21 siswa dituntut untuk cerdas, kreatif dan inovatif karena di masa yang akan datang sumber daya manusia Indonesia diharapkan menjadi SDM yang unggul dan mampu bersaing secara global. Hal tersebut dapat terwujud apabila siswa memiliki sumber informasi yang sangat luas. Informasi bisa didapat dengan cara membaca. Menurut Musfiroh dan Listyorini (2016), membaca dipandang sebagai komponen penting untuk kesuksesan sekolah dan siswa membutuhkan kemampuan membaca yang bagus untuk memahami dan memelajari materi yang beragam di kelas.

Berdasarkan hasil pengamatan penulis di salah satu SD Negeri yang ada di kota Cirebon bahwa sumber belajar yang digunakan guru sudah beragam. Selain buku, guru menggunakan media internet, lingkungan sekitar, dan lain-lain. Hal ini bertujuan untuk memudahkan siswa dalam mendapatkan informasi. Namun, perkembangan teknologi informasi tidak menunjukkan siswa gemar membaca, karena kegiatan siswa bermain gadget tidak digunakan untuk belajar, melainkan lebih cenderung digunakan untuk bermain sosial media dan permainan digital. Oleh sebab itu untuk meningkatkan minat baca siswa sekolah dasar dapat dilakukan dengan pembiasaan-pembiasaan rutin di sekolah melalui kegiatan literasi atau mengikuti ekstrakurikuler literasi yang diadakan di sekolah. Kegiatan literasi merupakan kemampuan mengakses, memahami, dan menggunakan sesuatu secara cerdas melalui berbagai aktivitas, antara lain membaca, melihat, menyimak, menulis dan/atau berbicara (Wandasari, 2017).

Tujuan umum gerakan literasi sekolah adalah menumbuhkembangkan budi pekerti peserta didik melalui pembudayaan ekosistem literasi sekolah yang diwujudkan dalam gerakan literasi sekolah agar mereka menjadi pembelajar

Caruban: Jurnal Ilmiah Pendidikan Dasar 3(1), 40-51, Januari 2020

DOI: http://dx.doi.org/10.33603/.v3i1.3361, p-ISSN 2615-1391, e-ISSN 2620-3219

CProdi PGSD Universitas Swadaya Gunung Jati 
sepanjang hayat (Surangangga, 2017). Sebagaimana yang dituangkan dalam peraturan menteri pendidikan dan kebudayaan nomor 23 tahun 2015 pasal 1 ayat 4 yang berbunyi "pembiasaan adalah serangkaian kegiatan yang harus dilakukan oleh siswa, guru, dan tenaga kependidikan yang bertujuan untuk menumbuhkan kebiasaan yang baik dan membentuk generasi berkarakter positif".

Sayangnya, kegiatan literasi belum terlalu marak dilaksanakan di sekolah sekolah karena beberapa kendala, diantaranya kurangnya pembiasaan membaca (literasi) di sekolah, lingkungan sekolah yang tidak kaya teks, kurang termanfaatkannya perpustakaan sekolah, belum adanya perpustakaan mini di kelas, serta belum adanya pojok baca di sekolah. Hal ini dapat diantisipasi minimal dengan melakukan pembiasaan wajib membaca bagi siswa selama 15 menit sebelum jam pelajaran dimulai setiap hari. Buku yang dibaca tidak harus buku pelajaran sekolah. Kegiatan literasi ini memiliki pengaruh yang sangat signifikan terhadap minat baca siswa (Kartika \& Nugrahanto, 2017; Faradina, 2017; dan Tantri \& Dewantara, 2017). Berdasarkan hal tersebut, penulis melaksanakan kegiatan penelitian pada salah satu sekolah dasar negeri di Kota Cirebon tentang pengaruh kegiatan literasi terhadap minat baca siswa di sekolah dasar.

\section{Metode}

Penelitian ini dilaksanakan menggunakan pendekatan kualitatif dengan penjelasan secara deskriptif pada data yang didapat. Subjek pada penelitian ini adalah siswa pada salah satu sekolah dasar di Kota Cirebon. Data penelitian dikumpulkan melalui observasi hasil kegiatan literasi pada program Cirebon Leader's Reading Challenge (CLRC) bernama Readhaton yang dijalankan selama delapan bulan dan mengharuskan siswa membaca minimal 12 buku serta membuat review-nya. Selain melalui observasi, data juga dikumpulkan melalui wawancara dengan kepala sekolah dan guru pembimbing kegiatan. Tahapan kegiatan readhaton adalah pembagian kelompok siswa, verifikasi (delapan tahap) disertai teknik review pada tiap tahapnya, serta akhir program. Pada tahap pembagian kelompok, siswa dibagi menjadi tiga kelompok, yaitu 1) kelas bawah, 2) kelas atas mula, dan 3) kelas atas mahir. Kelompok tersebut ditentukan berdasarkan tingkatan akademik, kelas tiga merupakan kelas bawah, kelas empat dan lima 
merupakan kelas atas mula, serta kelas lima dan enam merupakan kelas atas mahir. Untuk kelas lima yang terdapat dalam kategori kelas atas mula merupakan siswa yang baru mulai mengikuti literasi, sedangkan kelas lima yang ada pada kelas atas mahir sudah memiliki pengalaman dalam literasi.

Kategori kelompok literasi kelas bawah terdiri dari siswa kelas tiga yang berjumlah 14 orang. Kategori kelompok literasi kelas atas mula terdiri dari siswa kelas empat dan lima yang berjumlah 18 orang. Kategori kelompok literasi kelas atas mahir terdiri dari siswa kelas lima dan enam yang berjumlah 10 orang. Program Cirebon Leader's Reading Challenge (CLRC) dilakukan selama delapan bulan. Selama delapan bulan siswa harus melakukan verifikasi sebanyak delapan tahap. Masing-masing kategori menghasilkan bentuk review yang berbeda-beda.

Tabel 1. Macam-macam teknik Review

\begin{tabular}{|c|c|c|c|}
\hline \multirow[t]{2}{*}{ Verifikasi } & \multicolumn{3}{|c|}{ Kategori } \\
\hline & SD Bawah & SD Atas (Mula) & SD Atas (Mahir) \\
\hline Tahap 1 & $\begin{array}{l}\text { Setelah membaca, } \\
\text { siswa bertanya jawab } \\
\text { kemudian } \\
\text { menceritakan kembali, } \\
\text { memilih toko yang } \\
\text { paling disukai, dan } \\
\text { membuat review aku } \\
\text { dan tokoh (AT) }\end{array}$ & $\begin{array}{lr}\text { Setelah membaca, } \\
\text { siswa membuat } \\
\text { review fishbone } \\
\text { dengan teknik } \\
\text { menuliskan judul, } \\
\text { penulis, penerbit, apa } \\
\text { saja yang tedapat } \\
\text { dalam buku } \\
\text { mencakup apa, } \\
\text { mengapa, bagaimana, } \\
\text { siapa, dimana, dan } \\
\text { kapan, serta } \\
\text { menuliskan hikmah } \\
\text { setelah membaca } \\
\text { buku tersebut. }\end{array}$ & $\begin{array}{lr}\text { Setelah } & \text { membaca, } \\
\text { siswa } & \text { membuat } \\
\text { review r } & \text { Y-Chart } \\
\text { dengan } & \text { teknik } \\
\text { mencari } & \text { hikmah } \\
\text { yang terasa dalam } & \text { dacaan, membuat hal } \\
\text { bacan } & \text { terkesan terlihat } \\
\text { dalam bacaan, dan } \\
\text { hal terkesan } \\
\text { terdengar dalam } \\
\text { bacaan }\end{array}$ \\
\hline Tahap 2 & $\begin{array}{l}\text { Setelah membaca, } \\
\text { siswa bertanya jawab } \\
\text { kemudian } \\
\text { menceritakan kembali, } \\
\text { memilih toko yang } \\
\text { paling disukai, dan } \\
\text { membuat review aku } \\
\text { dan tokoh (AT) }\end{array}$ & $\begin{array}{lr}\text { Setelah } & \text { membaca, } \\
\text { siswa } & \text { membuat } \\
\text { review } & \text { fishbone } \\
\text { dengan } & \text { teknik } \\
\text { menuliskan judul, } & \text { penulis, penerbit, apa } \\
\text { saja yang tedapat } \\
\text { dalam } \\
\text { mencakup buku } \\
\text { mengapa, bagaimana, }\end{array}$ & $\begin{array}{lr}\text { Setelah } & \text { membaca, } \\
\text { siswa } & \text { membuat } \\
\text { review } & \text { Y-Chart } \\
\text { dengan } & \text { teknik } \\
\text { mencari hikmah } & \text { hang terasa dalam } \\
\text { yacaan, membuat hal } \\
\text { barkesan terlihat } \\
\text { terkan } \\
\begin{array}{l}\text { dalam bacaan, dan } \\
\text { hal terkesan }\end{array}\end{array}$ \\
\hline
\end{tabular}

Caruban: Jurnal Ilmiah Pendidikan Dasar 3(1), 40-51, Januari 2020

DOI: http://dx.doi.org/10.33603/.v3i1.3361, p-ISSN 2615-1391, e-ISSN 2620-3219

CProdi PGSD Universitas Swadaya Gunung Jati 


\begin{tabular}{|c|c|c|c|}
\hline \multirow[t]{3}{*}{ Verifikasi } & \multicolumn{3}{|c|}{ Kategori } \\
\hline & SD Bawah & SD Atas (Mula) & SD Atas (Mahir) \\
\hline & & $\begin{array}{l}\text { siapa, dimana, dan } \\
\text { kapan, serta } \\
\text { menuliskan hikmah } \\
\text { setelah membaca } \\
\text { buku tersebut. }\end{array}$ & $\begin{array}{l}\text { terdengar } \\
\text { bacaan }\end{array}$ \\
\hline Tahap 3 & $\begin{array}{lr}\text { Setelah membaca, } & \text { membuat } \\
\text { siswa peta cerita } \\
\text { review } \\
\text { berdasarkan tokoh } \\
\text { cerita yang disukai } \\
\text { dan latar. }\end{array}$ & $\begin{array}{lr}\text { Setelah membaca, } \\
\text { siswa membuat } \\
\text { review fishbone } \\
\text { dengan teknik } \\
\text { menuliskan judul, } \\
\text { penulis, penerbit, apa } \\
\text { saja yang tedapat } \\
\text { dalam raku } \\
\text { mencakup apa, } \\
\text { mengapa, bagaimana, } \\
\text { siapa, dimana, dan } \\
\text { kapan, serta } \\
\text { menuliskan hikmah } \\
\text { setelah membaca } \\
\text { buku tersebut. }\end{array}$ & $\begin{array}{lr}\text { Setelah membaca, } \\
\text { siswa membuat } \\
\text { review y-chart dengan } \\
\text { teknik mencari } \\
\text { hikmah yang terasa } \\
\text { dalam } \\
\text { membuat bacaan, } \\
\text { terkesan terlihat } \\
\text { dalam bacaan, dan } \\
\text { hal } \\
\text { terdengan terkesan } \\
\text { bacaan dalam }\end{array}$ \\
\hline Tal & $\begin{array}{lr}\text { Setelah membaca, } \\
\text { siswa membuat review } \\
\text { petaran } \\
\text { berdasarkan tokoh } \\
\text { cerita yang disukai } \\
\text { dan latar. }\end{array}$ & 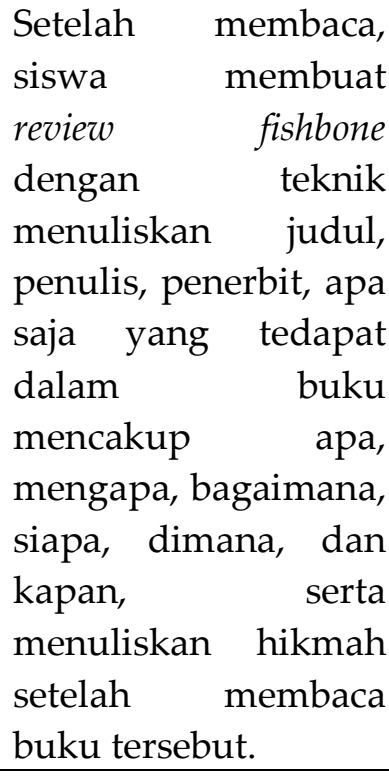 & 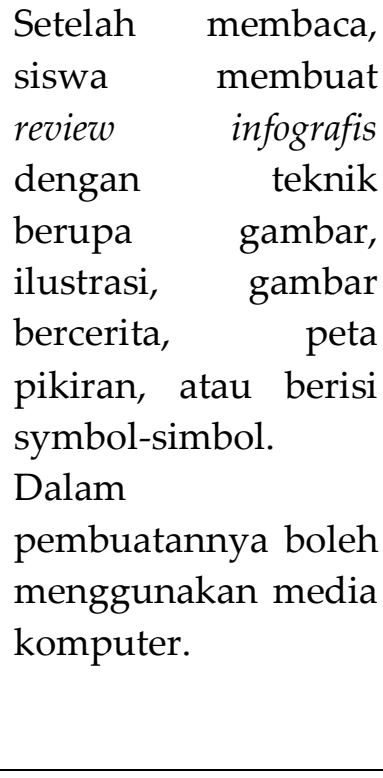 \\
\hline Tahap 5 & $\begin{array}{l}\text { Setelah membaca, } \\
\text { siswa membuat review } \\
\text { Flip Chart dengan } \\
\text { teknik menuliskan } \\
\text { judul buku, kemudian } \\
\text { menuliskan alur cerita } \\
\text { dari awal hingga } \\
\text { akhir. }\end{array}$ & $\begin{array}{l}\text { Setelah membaca, } \\
\text { siswa membuat } \\
\text { review AIH dengan } \\
\text { teknik menuliskan } \\
\text { Alasan membaca dan } \\
\text { memilih buku } \\
\text { tersebut, menjelaskan } \\
\text { isi tidak perlu }\end{array}$ & $\begin{array}{lr}\text { Setelah } & \text { membaca, } \\
\text { siswa } & \text { membuat } \\
\text { review } & \text { infografis } \\
\text { dengan } & \text { teknik } \\
\text { berupa } & \text { gambar, } \\
\text { ilustrasi, gambar } \\
\text { bercerita, } \\
\text { pikiran, atau berisi }\end{array}$ \\
\hline
\end{tabular}

Caruban: Jurnal Ilmiah Pendidikan Dasar 3(1), 40-51, Januari 2020

DOI: http://dx.doi.org/10.33603/.v3i1.3361, p-ISSN 2615-1391, e-ISSN 2620-3219

CProdi PGSD Universitas Swadaya Gunung Jati 


\begin{tabular}{|c|c|c|c|}
\hline \multirow[t]{3}{*}{ Verifikasi } & \multicolumn{3}{|c|}{ Kategori } \\
\hline & SD Bawah & SD Atas (Mula) & SD Atas (Mahir) \\
\hline & & 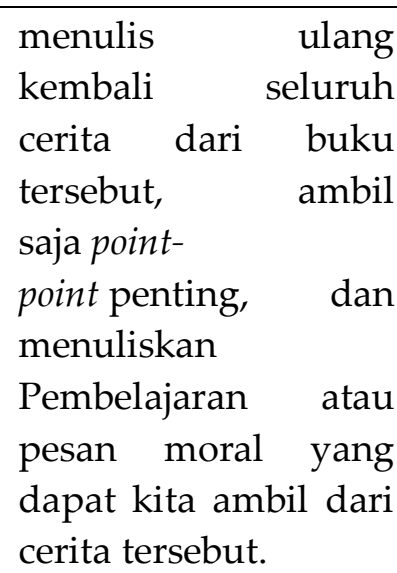 & $\begin{array}{l}\text { symbol-simbol. } \\
\text { Dalam } \\
\text { pembuatannya boleh } \\
\text { menggunakan media } \\
\text { komputer. }\end{array}$ \\
\hline Tahap 6 & $\begin{array}{l}\text { Setelah membaca, } \\
\text { siswa membuat review } \\
\text { Flip Chart dengan } \\
\text { teknik menuliskan } \\
\text { judul buku, kemudian } \\
\text { menuliskan alur cerita } \\
\text { dari awal hingga } \\
\text { akhir. }\end{array}$ & 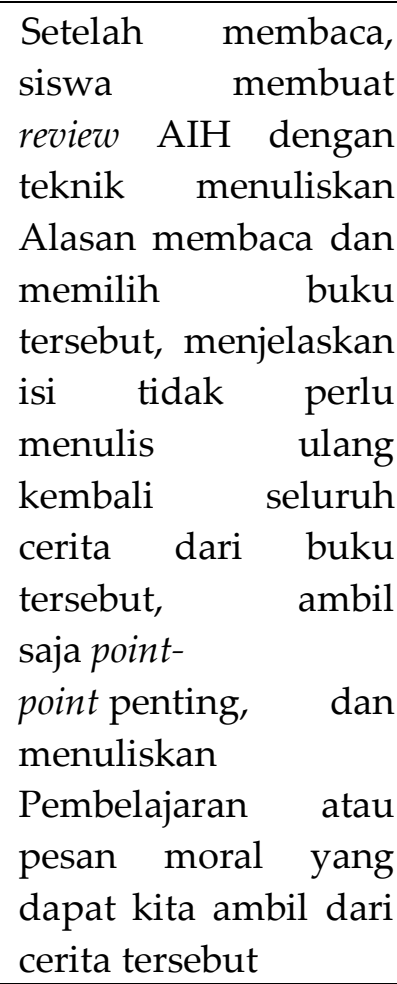 & 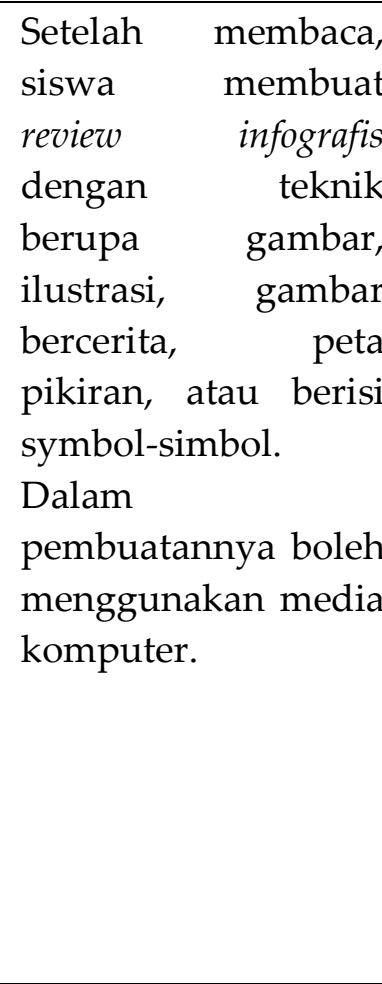 \\
\hline Tahap 7 & $\begin{array}{l}\text { Setelah membaca, } \\
\text { siswa membuat review } \\
\text { fishbone dengan teknik } \\
\text { menuliskan judul, } \\
\text { penulis, penerbit, apa } \\
\text { saja yang tedapat } \\
\text { dalam buku } \\
\text { mencakup apa, } \\
\text { mengapa, bagaimana, } \\
\text { siapa, dimana, dan } \\
\text { kapan, serta } \\
\text { menuliskan hikmah } \\
\text { setelah membaca }\end{array}$ & $\begin{array}{lr}\text { Setelah } & \text { membaca, } \\
\text { siswa } & \text { membuat } \\
\text { review AIH } & \text { dengan } \\
\text { teknik } & \text { menuliskan } \\
\text { alasan membaca dan } \\
\text { memilih } & \text { buku } \\
\text { tersebut, menjelaskan } \\
\text { isi tidak } & \text { perlu } \\
\text { menulis } & \text { ulang } \\
\text { kembali } & \text { seluruh } \\
\text { cerita dari } & \text { buku } \\
\text { tersebut, } & \text { ambil } \\
\text { saja point- } & \end{array}$ & $\begin{array}{l}\text { Setelah membaca, } \\
\text { siswa membuat } \\
\text { review resensi dengan } \\
\text { teknik menuliskan } \\
\text { judul buku, } \\
\text { pengarang, halaman, } \\
\text { nama pembaca, alur } \\
\text { isi buku keseluruhan, } \\
\text { pendapat tentang } \\
\text { buku, kelebihan dan } \\
\text { kekurangan, kritik, } \\
\text { dan saran, serta } \\
\text { simpulan. }\end{array}$ \\
\hline
\end{tabular}

Caruban: Jurnal Ilmiah Pendidikan Dasar 3(1), 40-51, Januari 2020

DOI: http://dx.doi.org/10.33603/.v3i1.3361, p-ISSN 2615-1391, e-ISSN 2620-3219

CProdi PGSD Universitas Swadaya Gunung Jati 


\begin{tabular}{|c|c|c|c|}
\hline \multirow[t]{3}{*}{ Verifikasi } & \multicolumn{3}{|c|}{ Kategori } \\
\hline & SD Bawah & SD Atas (Mula) & SD Atas (Mahir) \\
\hline & buku tersebut. & $\begin{array}{l}\text { point penting, dan } \\
\text { menuliskan } \\
\text { pembelajaran atau } \\
\text { pesan moral yang } \\
\text { dapat kita ambil dari } \\
\text { cerita tersebut. }\end{array}$ & \\
\hline Tahap 8 & $\begin{array}{l}\text { Setelah membaca, } \\
\text { siswa membuat review } \\
\text { fishbone dengan teknik } \\
\text { menuliskan judul, } \\
\text { penulis, penerbit, apa } \\
\text { saja yang tedapat } \\
\text { dalam buku } \\
\text { mencakup apa, } \\
\text { mengapa, bagaimana, } \\
\text { siapa, dimana, dan } \\
\text { kapan, serta } \\
\text { menuliskan hikmah } \\
\text { setelah membaca } \\
\text { buku tersebut. }\end{array}$ & $\begin{array}{l}\text { Setelah membaca, } \\
\text { siswa membuat } \\
\text { review AIH dengan } \\
\text { teknik menuliskan } \\
\text { alasan membaca dan } \\
\text { memilih } r \text { buku } \\
\text { tersebut, menjelaskan } \\
\text { isi tidak perlu } \\
\text { menulis } \\
\begin{array}{l}\text { kembali ulang } \\
\text { cerita dari buku } \\
\text { tersebut, } \\
\text { saja point- ambil } \\
\text { point penting, dan } \\
\text { menuliskan } \\
\text { pembelajaran atau } \\
\text { pesan moral yang } \\
\text { dapat kita ambil dari } \\
\text { cerita tersebut }\end{array}\end{array}$ & $\begin{array}{l}\text { Setelah membaca, } \\
\text { siswa membuat } \\
\text { review resensi dengan } \\
\text { teknik menuliskan } \\
\text { judul buku, } \\
\text { pengarang, halaman, } \\
\text { nama pembaca, alur } \\
\text { isi buku keseluruhan, } \\
\text { pendapat tentang } \\
\text { buku, kelebihan dan } \\
\text { kekurangan, kritik, } \\
\text { dan saran, serta } \\
\text { simpulan. }\end{array}$ \\
\hline
\end{tabular}

Pada akhir program Cirebon Leader's Reading Challenge (CLRC) siswa yang berhasil membaca sebanyak 12 buku untuk SD bawah dan 24 buku untuk SD atas selama delapan bulan, dan membuat review tiap tahap (1-8) akan mendapatkan penghargaan berupa medali dan sertifikat CLRC, serta berhak mengikuti jambore literasi di kota Cirebon. Berdasarkan hasil wawancara oleh narasumber dengan adanya kegiatan literasi tersebut siswa SD banyak termotivasi untuk membaca buku. Selain itu dengan adanya kegiatan literasi dengan menggunakan tantangan tersebut siswa semakin terpacu untuk berhasil dan sudah ada banyak siswa yang berhasil menyelesaikan tantangan tersebut dengan baik. 


\section{Hasil dan Pembahasan}

Program Cirebon Leader's Reading Challenge (CLRC) merupakan salah satu langkah yang tepat untuk meningkatkan minat baca siswa. Damrin (2015) menyatakan bahwa minat membaca anak adalah suatu perhatian yang kuat dan mendalam disertai dengan perasaan senang terhadap kegiatan membaca sehingga mengarahkan anak untuk membaca dengan kemauannya sendiri. Jadi dengan mengikuti kegiatan literasi CLRC tersebut siswa menjadi gemar membaca karena terbiasa, dan sadar akan pentingnya membaca dalam mengolah informasi yang didapat. Hal ini dapat terlihat ketika banyak siswa yang berhasil dalam mengikuti CLRC.

Untuk kategori siswa SD bawah, setiap anak telah berhasil menyelesaikan tantangan dengan baik dan membuat hasil review dari buku yang telah dibaca sebanyak 12 buku. Terdiri dari hasil review berupa aku dan tokoh dari tiga buku, peta cerita dari tiga buku, flip chart dari tiga buku, dan fishbone dari tiga buku. Review Aku dan tokoh merupakan ulasan dari sebuah buku yang telah dibaca dengan cara membaca nyaring dan memilih tokoh yang paling disukai kemudian menuliskan alasan kenapa menyukai tokoh tersebut. Peta cerita adalah sarana untuk menulis cerita agar lebih baik dari segi plot, karakter, dan pengembangan cerita. Dan flip chart adalah kumpulan ringkasan, skema, gambar, tabel yang dibuka secara berurutan, tersusun dengan rapi dan baik berdasarkan topik. Serta fishbone adalah bentuk ulasan yang digunakan untuk mengidentifikasi dan menunjukkan hubungan sebab dan akibat. Keberhasilan kategori kelas bawah dapat terlihat pada Tabel 2 sebagai berikut.

Tabel 2. CLRC SD Bawah

\begin{tabular}{lcccc}
\hline No & Nama Siswa & Kelas & $\begin{array}{c}\text { Kategori } \\
\text { SD- Bawah }\end{array}$ & $\begin{array}{c}\text { Jumlah Hasil } \\
\text { Review Buku }\end{array}$ \\
\hline 1. & SB-1 & 3 & $\sqrt{ }$ & 12 \\
\hline 2. & SB-2 & 3 & $\sqrt{ }$ & 12 \\
\hline 3. & SB-3 & 3 & $\sqrt{ }$ & 12 \\
\hline 4. & SB-4 & 3 & $\sqrt{ }$ & 12 \\
\hline 5. & SB-5 & 3 & $\sqrt{ }$ & 12 \\
\hline 6. & SB-6 & 3 & $\sqrt{ }$ & 12 \\
\hline 7. & SB-7 & 3 & $\sqrt{ }$ & 12 \\
\hline 8. & SB-8 & 3 & $\sqrt{ }$ & 12 \\
\hline
\end{tabular}

Caruban: Jurnal Ilmiah Pendidikan Dasar 3(1), 40-51, Januari 2020

DOI: http://dx.doi.org/10.33603/.v3i1.3361, p-ISSN 2615-1391, e-ISSN 2620-3219

OProdi PGSD Universitas Swadaya Gunung Jati 


\begin{tabular}{|c|c|c|c|c|}
\hline No & Nama Siswa & Kelas & $\begin{array}{c}\text { Kategori } \\
\text { SD- Bawah }\end{array}$ & $\begin{array}{l}\text { Jumlah Hasil } \\
\text { Review Buku }\end{array}$ \\
\hline
\end{tabular}

\begin{tabular}{lllll}
\hline 9. & SB-9 & 3 & $\sqrt{ }$ & 12 \\
\hline 10. & SB-10 & 3 & $\sqrt{ }$ & 12 \\
\hline 11. & SB-11 & 3 & $\sqrt{ }$ & 12 \\
\hline 12. & SB-12 & 3 & $\sqrt{ }$ & 12 \\
\hline 13. & SB-13 & 3 & $\sqrt{ }$ & 12 \\
\hline 14. & SB-14 & 3 & $\sqrt{ }$ & 12 \\
\hline
\end{tabular}

Kemudian untuk kategori SD atas mula, masing-masing siswa telah menyelesaikan tantangan dengan baik, yaitu membuat hasil review dari 24 buku. Dua belas buku berupa fishbone yang merupakan bentuk ulasan yang digunakan untuk mengidentifikasi dan menunjukkan hubungan sebab dan akibat, dan dua belas buku

berupa AIH, yang merupakan singkatan dari alasan, isi dan hikmah. Sedangkan untuk Keberhasilan kategori kelas atas mula dapat terlihat pada Tabel 3.

Tabel 3. CLRC SD Atas Mula

\begin{tabular}{lcccc}
\hline No & Nama Siswa & Kelas & $\begin{array}{c}\text { Kategori } \\
\text { SD- Atas Mula }\end{array}$ & $\begin{array}{c}\text { Jumlah Hasil } \\
\text { Review Buku }\end{array}$ \\
\hline 1. & SAM-1 & 4 & $\sqrt{ }$ & 24 \\
\hline 2. & SAM-2 & 4 & $\sqrt{ }$ & 24 \\
\hline 3. & SAM-3 & 4 & $\sqrt{ }$ & 24 \\
\hline 4. & SAM-4 & 4 & $\sqrt{ }$ & 24 \\
\hline 5. & SAM-5 & 4 & $\sqrt{ }$ & 24 \\
\hline 6. & SAM-6 & 4 & $\sqrt{ }$ & 24 \\
\hline 7. & SAM-7 & 4 & $\sqrt{ }$ & 24 \\
\hline 8. & SAM-8 & 4 & $\sqrt{ }$ & 24 \\
\hline 9. & SAM-9 & 4 & $\sqrt{ }$ & 24 \\
\hline 10. & SAM-10 & 4 & $\sqrt{ }$ & 24 \\
\hline 11. & SAM-11 & 4 & $\sqrt{ }$ & 24 \\
\hline 12. & SAM-12 & 4 & $\sqrt{ }$ & 24 \\
\hline 13. & SAM-13 & 4 & $\sqrt{ }$ & 24 \\
\hline 14. & SAM-14 & 4 & $\sqrt{ }$ & 24 \\
\hline 15. & SAM-15 & 4 & $\sqrt{ }$ & 24 \\
\hline 16. & SAM-16 & 5 & $\sqrt{ }$ & 24 \\
\hline 17. & SAM-17 & 5 & $\sqrt{ }$ & 24 \\
\hline 18. & SAM-18 & 5 & $\sqrt{ }$ & 24 \\
\hline
\end{tabular}


Selanjutnya kategori SD atas mahir pun masing-masing siswa telah berhasil menyelesaikan tantangan dengan baik, yaitu membuat hasil review dari 24 buku. Duabelas buku hasil review berupa Y-chart, merupakan bentuk laporan hal yang dapat dirasa,dilihat, dan didengar dari buku yang telah dibaca. Delapan buku hasil review berupa Infografis, merupakan bentuk penyajian data dengan konsep visual yang terdiri dari teks dengan tambahan gambar ilustrasi yang menarik. Empat buku hasil review berupa resensi buku, merupakan ulasan untuk mengetahui kelebihan dan kekurangan buku, memberikan gambaran pada pembaca secara ringkas, memberi masukan berupa kritik dan saran,dll. Keberhasilan kategori kelas atas mahir dapat terlihat pada Tabel 4.

Tabel 4. CLRC SD Atas Mahir

\begin{tabular}{lcccc}
\hline No & Nama Siswa & Kelas & $\begin{array}{c}\text { Kategori } \\
\text { SD- Atas } \\
\text { Mahir }\end{array}$ & $\begin{array}{c}\text { Jumlah Hasil } \\
\text { Review Buku }\end{array}$ \\
\hline 1. & SA-1 & 5 & $\sqrt{ }$ & 24 \\
\hline 2. & SA-2 & 5 & $\sqrt{ }$ & 24 \\
\hline 3. & SA-3 & 5 & $\sqrt{ }$ & 24 \\
\hline 4. & SA-4 & 5 & $\sqrt{ }$ & 24 \\
\hline 5. & SA-5 & 5 & $\sqrt{ }$ & 24 \\
\hline 6. & SA-6 & 5 & $\sqrt{ }$ & 24 \\
\hline 7. & SA-7 & 6 & $\sqrt{ }$ & 24 \\
\hline 8. & SA-8 & 6 & $\sqrt{ }$ & 24 \\
\hline 9. & SA-9 & 6 & $\sqrt{ }$ & 24 \\
\hline 10. & SA-10 & 6 & $\sqrt{ }$ & 24 \\
\hline
\end{tabular}

Meskipun banyak siswa yang berhasil, program ini memiliki beberapa hambatan yakni peran orang tua dalam mendukung anaknya masih belum merata. Karena masih saja ada orang tua yang kurang perhatian terhadap anak. Selain itu waktu guru dalam membimbing anak juga merupakan hambatan yang ada dalam program ini. Karena guru tidak memiliki waktu yang panjang dalam membimbing siswa untuk literasi dan membuat hasil review.

Dalam kegiatan program Cirebon Leader's Reading Challenge (CLRC) terdapat beberapa hal yang dapat menunjang siswa untuk berhasil menyelesaikan tantangan yaitu siswa sangat antusias untuk membiasakan diri membaca 
buku yang dilakukan secara bersamaan (Readhaton), dilakukan sebelum pembelajaran dimulai setiap hari sabtu. Selain itu, siswa diberi kebebasan untuk memilih buku bacaan sesuai dengan yang disukai namun masih dalam pantauan guru dari layak atau tidaknya buku tersebut, sehingga siswa tidak merasa bosan untuk membaca. Keberhasilan siswa secara menyeluruh dalam menyelesaikan tantangan ini menunjukkan bahwa kegiatan CLRC memiliki pengaruh terhadap minat baca siswa SD menjadi lebih baik karena kegiatan CLRC dapat mengurangi siswa dalam bermain gadget dan memilih untuk gemar membaca.

\section{Simpulan dan Rekomendasi}

Berdasarkan pembahasan di atas, maka dapat disimpulkan bahwa kegiatan literasi CLRC berpengaruh terhadap minat baca siswa SD. Kegiatan CLRC merupakan kegiatan literasi menggunakan tantangan dan buku yang dibaca siswa berdasarkan keinginannya sendiri, dan siswa tidak hanya membaca buku tetapi siswa juga dapat menulis dengan cara membuat hasil review berupa peta cerita, flip chart, infografis, resensi, dan lain-lain. Keberhasilan siswa dalam menyelesaikan tantangan dengan baik dan mendapatkan penghargaan menunjukkan bahwa minat baca siswa SD menjadi lebih baik. Berdasarkan penemuan selama melaksanakan penelitian, penulis dapat merekomendasikan hal-hal berikut untuk mengatasi permasalahanpermasalahan yang ditemui, yakni guru diharapkan lebih aktif mengoordinasikan kegiatan literasi ini kepada orang tua siswa agar mereka dapat lebih intens dalam mendampingi anak-anaknya sehingga dapat menyelesaikan program lebih baik lagi, hal lain yang tak kalah pentingnya adalah guru secara khusus mengalokasikan waktunya lebih banyak untuk membimbing siswa dalam literasi dan membuat riview.

\section{Daftar Pustaka}

Musfiroh,T \& Listyorini,B. (2016). Konstruk Kompetensi Literasi Untuk Siswa Sekolah Dasar. Jurnal Litera 15 (1).

Wandasari, Y. (2017). Implementasi Gerakan Literasi Sekolah (Gls) Sebagai Pembentuk Pendidikan Berkarakter. Jurnal Manajemen, Kepemimpinan, dan Supervisi Pendidikan 1 (1).

Surangangga, (2017). Mendidik Lewat Literasi Untuk Pendidikan Berkualitas. Jurnal penjaminan mutu 3 (2). 
Faradina, N. (2017). Pengaruh Program Gerakan Literasi Sekolah Terhadap Minat Baca Siswa Di Sd Islam Terpadu Muhammadiyah An-Najah Jatinom Klaten. Jurnal Hanata Widya 6 (8).

Tantri \& Dewantara. (2017). Keefektifan Budaya Literasi Di Sd N 3 Banjar Jawa Untuk Meningkatkan Minat Baca. Journal of Education Research and Evaluation 1 (4).

Kartika \& Nugrahanto. (2014). Mengembangkan Minat Baca Di Masyarakat Desa Pasanggrahan Dan Desa Malongpong Kecamatan Maja Kabupaten Majalengka. Jurnal aplikasi ipteks untuk masyarakat 3 (1).

Damrin . (2015). Minat Baca Siswa Kelas Rendah Dalam Pelaksanaan Literasi Sekolah Di Sd Islam Al Azhar 34 Makassar. Jurnal pendidikan 5 (1). 